\title{
17. Permanent revolution: Occupying democracy
}

\author{
Douglas Rushkoff
}

\begin{abstract}
The Occupy movement constitutes an upgrade of political activism from campaign to prototype. This shift from the traditional narrative, goaloriented movement to activism as 'infinite game' is consistent with the changing media environment informing this activity. As we move from a culture defined by the book and broadcast media to one expressed more through the net and peer-to-peer media, our approaches to politics and our expectations for its results change. We are transitioning from a spectator democracy, in which citizens project their hopes and dreams onto charismatic leaders, to a participatory democracy, in which citizens enact change through their real-time interactions. This shift reflects more than a change in communications technologies; it marks a change in the mode and dimensional level of activism.
\end{abstract}

Keywords: Occupy movement, political activism, peer-to-peer media, participatory democracy, global justice movement, prototyping

Back in the late 1990s, I became interested in the potential of interactive and networking technologies to enhance the potential for democratic and civic participation. I wrote a short book entitled Open source democracy (Rushkoff 1998), in which I outlined what I saw as the opportunity for deeper levels of public intervention in not just electoral politics, but ongoing civic affairs. At the time, most visions of electronically enabled democracy were still stuck in what we might call the Ross Perot phase: use the net to let people vote or participate in what the third-party presidential candidate called "electronic town halls" (Simon 1992). Perot envisioned citizens watching

Glas, R., S. Lammes, M. de Lange, J. Raessens, and I. de Vries, eds. 2019. The Playful Citizen. Civic Engagement in a Mediatized Culture. Amsterdam: Amsterdam University Press. DOI: 10.5117/9789462984523/CH17 
television programs that informed them about the issues, and then voting yes or no to proposals through their remote controls.

Meanwhile, Clinton pollster Dick Morris (Martinson 2000) saw in the internet a new path to polling accuracy. Instead of calling people and asking them questions, internet pollsters could send emails and monitor existing discussion groups and comments sections. While feedback from users would not directly influence policy, at least lawmakers would be able to gauge (and presumably change messaging in order to influence) public opinion.

My own hope was for a deeper level of participation. Just as the internet allowed former television viewers to create something very much like programming, the internet could allow former voters to create something very much like policy platforms. The law might come to resemble less a set of bound volumes than a participatory wiki.

The 2004 Howard Dean campaign was among the first to respond to this call for a more net-enabled democracy. Dean's campaign manager, Joe Trippi, used the language of open source democracy to energize the first sustained and successful internet political fundraising campaign. Instead of taking large sums from a small group of donors, Dean drew support from thousands upon thousands of individuals whose donations averaged just $\$ 8$. Nevertheless, the $\$ 50$ million Dean raised made him the first presidential candidate to forgo federal matching funds (Trippi 2004).

Eventually, the Obama campaign followed suit, using Facebook, Twitter, Meetup, forums, and a state-of-the-art website to solicit campaign donations, organize on-the-ground get-out-the-vote activities, and generate peer-to-peer support for his candidacy. He, too, raised enough money to reject federal campaign funds, and managed to leverage the internet's metaphorical value as a participatory medium to cast his candidacy as a bottom-up people's revolution.

However, after Obama won, the stirring idea that 'we are the change we have been waiting for' quickly devolved into politics as usual. While Obama the net-enabled campaigner offered many ways for people to get involved by donating money or getting others to donate money, Obama the net-enabled office-holder used the net much less aggressively. The administration offered greater transparency than its predecessors, making it easier for citizens to find pending legislation on the web. But for the most part, it was still a read-only government. The net was used to gather the troops for the campaign, but not to solicit or enable their participation as citizens in an ongoing way. For those who may have risen to the call to "be the change" (Sullivan 2008) this was a disappointment. 
But the media attention garnered through YouTube-sponsored debates and national net-organized Meetups spurred dozens of pop culture and commercial copycats. Internet-style democracy founds its expression in everything from American Idol (where viewers use text messaging to vote for their favorite singers) to a campaign for Mountain Dew called 'Dewmocracy' where consumers campaign for name and color of the next Mountain Dew beverage offering (Rushkoff 2009). This gamification is not an entry point for democratic participation, but rather vulgarizes democracy as some form of consumer decision. Instead of using the net to increase opportunity, engagement, and levels of knowledge, the net seems to be used in the opposite fashion: Internet-style democracy encourages impulsiveness, impatience, siloing, and closed-minded hostility (Pariser 2011). CNN and other news networks now use scientific-looking 'people meters' to gauge instantaneous audience responses to candidates' speeches and debates. A line at the bottom of the screen indicates male and female enthusiasm for whatever a candidate is saying in that moment - as if the immediate reaction and the considered response were one and the same (Goodman, Rushkoff, and Dretzin 2003).

Meanwhile, the amateurization encouraged by the net leads users to believe that access means ability (Keane 2007). Just because someone has access to a blog does not mean he or she has the ability to write researched, considered or even logical posts. Since a Wordpress template can now make anyone's posts appear — at least superficially — as authoritative as anyone else's, it is up to readers to distinguish between the veracity and sense of different voices, including their own.

But in a media environment where sensationalism still trumps sense, the reward for participation is not to gain or share knowledge or insight, but to be credited with hits. Bloggers get attention for saying outrageous things, or linking to those who have. With the tools to publish becoming equated with the skill to write, the amateur is rendered incapable of distinguishing his own off-the-cuff output from the considered, researched, or reported product of trained professionals. This in turn leads to a misplaced disgust for professional journalism - a sense that those who earn column space in The New York Times or airtime on the BBC do not offer anything of greater intrinsic value than people posting in the comments sections or unvetted Tumblr blogs. I have more than once been questioned by college students wanting to know why I should be paid for doing "exactly the same thing" that they are doing for free.

Of course, the notion that no one should be paid for journalism misses the fact that corporations and governments will continue to pay billions 
to public relations firms and advertising agencies to obfuscate the truth. If society invests nothing in professional journalism, there will be no one left with the time, resources, and ability to deconstruct the fictions, pursue leads, evaluate sources, and confirm facts (Rushkoff 2010). Instead, we get an internet-inspired ontological relativism where everyone's opinions matter as much as everyone else's facts. Again, without some discipline and direction - some conscious sense of the structural biases of digital media - the promise of some kind of constructive, open source democracy moves ever further away.

In my own experience, I was scheduled to deliver a talk at an American college and received an email from a young woman who wanted to know whether or not I was a "leftist." It seems she had been retained by an organization headed by right-wing activist David Horowitz to protest the hiring of leftist speakers and professors at American colleges (Horowitz 2006). The young woman had spent a bit of time on my website reading articles, but had been as of yet unable to ascertain if I was, indeed, a leftist. "Could you just tell me if you are a leftist, so I know whether to protest your appearance?"

I responded that it would be difficult for me to answer. I had read much of Marx and understood the extraction of value from the worker, but I was not convinced that large-scale labor unions were the best vehicle for correcting the wrongs of corporate capitalism. She replied, asking if I could give her a simple "yes or no answer." I told her "yes and no." She declined my invitation to appear with me to discuss all this on stage during my appearance. This young woman was ready to protest based on my binary response, but unprepared to have an extended conversation — even through email—where she could become educated or even just hone and advance her own argument. She wanted something as easy as the like button on Facebook.

By amplifying the more gamified, amateur, and impulse-driven qualities of the net, e-democracy has not only missed the mark as an opportunity for a more participatory electorate and civic body, but also exacerbated some of the least productive elements of spectator democracy so many believed would be obsolesced by the internet (McLuhan 1992). However, while the net may have failed democracy as a tool or platform, it may have succeeded on a more subtle yet ultimately deeper level as a media environment. That is, while the keyboards and websites and blogs and streaming video and social networks actually comprising the internet may not be directly impacting the ways in which citizens engage in civics, digital technology as a cultural landscape is beginning to have a profound effect on the way people conceive of themselves in relationship to one another and institutions. 
Most significantly, as I'll attempt to show in the case of the Occupy Wall Street movement, the net suggests new metaphors and demonstrates new principles that inform a novel amalgam of activist practices.

In short, the 'playful citizen' now being discussed in many forums and collections like the one in which this chapter appears, is most interesting - and ultimately promising — as a style of inquiry into the ways that the emergence of the net and accompanying changes in the social-scientific paradigm have altered our expectations of agency, participation, and change.

\section{Digital environment}

The digital environment, like any other media environment, is embedded with certain values that inform the culture within it. The textual environment encouraged new ways of thinking about accountability (written contracts), human interaction (written law) and even religion (the written Covenant with God—the Torah) (Logan 1987; Ong 2002). The printing press likewise changed the way people related to business (central banking), government (the Enlightenment), and the authority of the Church (personal Bibles and the Protestant reformation) (McLuhan 1962).

To parse the impact of the digital environment is a bit more difficult since we are currently living within its effects. I identify four of the most pronounced conceptual shifts accompanying digitality in order to demonstrate the ways the Occupy movement has utilized them as central operating principles for its new approach to activism and democratic participation.

Feedback. The first is the notion of feedback. Traditionally, what we think of as feedback is simply the latent results of particular causes. Farmers plant in one season, and get feedback months later in the yield of crop. Plant seed too close together, and the crop compete for resources. This data is then incorporated into the next year's planting. Likewise, businesses send a product to market and then wait for sales reports to determine if the design and marketing were appropriate or could be improved upon. Each new iteration of planting or product design was based on the feedback from the one before.

In the dawn of the digital era, Cyberneticist Norbert Weiner (1965) saw in feedback a way of developing robots that could instantaneously 'feel' and respond to changing conditions in the real world. Just as a thermostat senses the temperature in order to turn a heater on or off, and an elevator 'feels' for indicators at each floor instead of attempting to measure the distance between one floor and another, robots could be taught to rely to no greater 
extent on their programming than to the things around them. Each piece of feedback could be iterated into the next action.

With the help of systems theorists aided by computers (Miller and Page 2007), much more complex systems could be analyzed in terms of feedback and iteration. The screech one hears when placing a microphone too close to an amplified speaker — what we call feedback —is really just the cyclical loop of uncontrolled feedback, iterating back to the microphone and again to the speaker. It is analogous to any of the many chaotic systems from the weather to the stock market that evade the analysis of our normal faculties.

Computers give us a way to see such systems in terms of their feedback and iteration. Fractals - the paisley graphics churned out by computers - are really just visualizations of the feedback and iteration of non-linear equations. Their power is in their ability to render previously incomprehensible systems in graphics that make sense to the human viewer. As a result, we become increasingly ready to understand feedback as an ongoing phenomenon rather than some occasional event.

In politics, for example, feedback used to occur primarily in four-year cycles. The populace would vote for a president, that president would go about his job, and then four years later he would get feedback in the form of being granted another term or kicked out of office. Pollsters arose to obtain feedback at tighter intervals, so that a politician could adjust policy (or even just his communication about policy) during his term. Digital technology — from live Twitter feeds to real time people meter results-now allows for instantaneous feedback. In a digital environment, feedback and iteration fold into one another.

Deconstruction of narrative. Likewise, in a digital environment, narratives no longer work quite like they used to. Thanks to the remote control, the DVR, the joystick, and the mouse, traditional stories are deconstructed, channel surfed, and fast-forwarded (Rushkoff 1995). The effects of the Aristolean arc and the hero's journey alike depended on a captive audience. With escape as close as the push of a button, audiences of all kinds become intolerant of the anxiety associated with the rising tension of a story.

In the deconstructed, cut-and-paste mash-up of digital media, the messianic, ends-justify-the-means values of traditional journeys no longer find an environment consonant with their value systems. This is the realm of ongoing fantasy role-playing, not tragically terminal heroes. The digital environment is not a place for extended struggles, charismatic leaders followed by masses, or winner-takes-all campaigns. The structure of digital entertainment and problem-solving is less like agonistic play with victors and vanquished than it is like James Carse's "infinite game” (Carse 1997)—one 
played for the sake of play. The object of the game is to keep the game going as long as possible.

Prototyping. This sensibility extends to the third characteristic of the digital media environment, its emphasis on prototyping over product. The shareware culture of the internet led to what are known as 'public betas' - the release of unfinished software to the public for testing and improvement. As Media Lab director Joichi Ito has explained (Ito 2011), there is no point testing a product in-house when there is a willing population of users out there ready to bang on one's programs. Besides, there is no time (see feedback and iteration above) to finish a product before seeing how people are going to react to it. Better to incorporate feedback into one's software in an ongoing fashion.

Programmer or player. Fourth and finally, the digital environment blurs the boundary between users and programmers. In a computing environment (unless a program is intentionally and artificially encrypted and protected) one's level of participation is only limited by one's willingness to learn more and dig deeper. One can play music through iTunes, or become a DJ whose selections are listened to by others. He can go deeper and use Garage Band to make new music, or another program to create new instruments for Garage Band. Or he can learn to program a new kind of music sequencer altogether.

Or, as I (Rushkoff 2012) and Julian Kücklick (2004) have explored separately, one's level of participation in any system can now be understood through the lens of a programmer or player. One can play a computer game out of the box; one can learn the 'cheat' codes to play the game on a new level; one can learn to 'mod' his own level of the game; or one can become a programmer and develop his own game. In a digital society, people participate on all these levels, and their limitations are either voluntary or visibly imposed.

\section{Occupy movement}

The Occupy movement bears all four of these characteristics of the digital media environment - and its success may have less to do with any immediate goals being met or elections being won than the extent to which these values are internalized by politics at large. As an Editor-at-Large for Adbusters magazine in the 199os and later author of the book Life inc (Rushkoff 2009), which deconstructed the corporation and sought new bottom-up solutions to capitalism, I was at least tangentially involved in laying some of the groundwork for this movement's ethos and methodology. 
When the Occupation was first announced, I decided to remain a distant supporter-so as not to either take credit for what was going on, or to unduly influence a movement of young people who I believed deserved to do this for themselves. In short, I fully believed the Occupiers would be capable of planning and interacting in ways beyond my own ability or foresight.

The first time I visited Zuccotti Park, during the first week of the Occupation, I had originally intended to speak and offer support. But on my arrival, I saw not just one but several cultural heroes of the 196os through the 199os, all preaching to the assembled activists, or singing songs with guitars, or giving interviews to the press. From my perspective, these folk figures meant well—but were ultimately usurping the moment from their ideological successors. So instead, I spent that day and several more simply observing the proceedings, asking questions, participating in teach-ins, and keeping my identity to myself.

My participation was entirely 'real world.' I did not check any of the social networks or Facebook pages for news, as I seemed to be learning enough on the ground. In fact, it did not even occur to me to use Facebook to learn what I could in real life. While this may imply a certain elitism, in that only those with the means to get to Zuccotti Park could experience what it was, the notion that this entire demonstration was enabled by social media implies that participants came entirely from one side of the digital divide. Yet, the fact that both real world and virtual means of participation remained available throughout at least this phase of Occupy suggests that neither is true. Social media competency was not a prerequisite for participation. This is not to say Occupy was divorced from social media at all. The activities I saw on site, however, mirrored the kinds of insights and behaviors garnered from what I believe were the participants' experiences_-both direct and indirect - of the digital media environment.

For instance, Occupiers have an altogether new relationship to feedback than traditional political movements. Although they occasionally march and shout, the majority of activity is not directed at or to anyone. Rather, it is lateral. Occupiers are more focused on one another than the stockbrokers who may curse their encampment from the periphery. The Occupation is a form of self-education. Rather than looking for signs that their message has been 'heard' by a politician or incorporated into some party's platform, they seek instead to develop coherence together.

The result is less like the feedback and iteration of an election cycle, where the constituency feeds back to the elected official, and more like the feedback and iteration of a fractal or dynamic system. As such, it remains unrecognizable as a form of politics to those still entirely within the printing 
press or broadcast modality, yet absolutely activist to participants within a digital environment.

Likewise, the Occupy movement is non-narrative, perhaps even to a fault given the practicalities of our still largely broadcast-centric media culture. The main critique by mainstream media of the Occupy movement is its seeming inability to articulate clear goals or demands. This is at least part of why mainstream television news reporters appeared so determined to cast Occupy Wall Street as the random, silly blather of an ungrateful and lazy generation of weirdos. As if defending against the coming obsolescence of their own truncated news formats, television journalists reported that the movement's inability to articulate its agenda in ten seconds or less meant there was no agenda at all. CNN business anchor Erin Burnett covered the goings on at Zuccotti Park in a segment called Seriously?! (Burnett 2011) "What are they protesting?" she asked, "nobody seems to know." Like Tonight Show comedian host Jay Leno's testing random mall patrons on American History, her main objective was to prove that the protesters did not know that the United States government had been reimbursed for the bank bailouts. More predictably, a Fox News reporter appeared flummoxed when the occupier he interviewed refused to explain how he wants the protests to "end." Attempting to transcend the standard political narrative, the protester explains: “As far as seeing it end, I wouldn't like to see it end. I would like to see the conversation continue" (Christopher 2011).

In this sense, whether or not its economic agenda is grounded in reality, Occupy Wall Street does constitute the first truly post-narrative political movement. Unlike the civil rights protests, labor marches, or even the Obama campaign, it does not take its cue from a charismatic leader, it does not express itself with bumper-sticker-length goals, nor does it understand itself as having a particular endpoint. The lack of specific goals makes it hard to maintain focus. The movement may be attempting to embrace too wide an array of complaints, demands, and goals: the collapsing environment, labor standards, housing policy, government corruption, World Bank lending practices, unemployment, increasing wealth disparity, and so on. Different people have been affected by different aspects of the same system - and they believe they are symptoms of the same core problem. What upsets banking's defenders and traditional Democrats alike is the refusal of this movement to state its terms or set its goals in the traditional language of campaigns.

But the Occupiers are simply native to a different media environment than its detractors. Unlike a political campaign designed to get some person in office and then close up shop (as in the election of Obama and subsequent youth disillusionment), this is not a movement with a traditional narrative 
arc. It is not about winning some debate point and then going home. Rather, as the product of the decentralized networked-era culture, it is less about victory than sustainability. It is not about one-pointedness but inclusion. It is not about scoring a victory, but groping toward consensus. It is not like a book or television, it is like the internet.

The Occupy movement is also imbued with digital culture's emphasis on prototyping. The encampments are no more a form of symbolic protest than they are a workshop for prototyping new methods and reviving old methods of political engagement. They are beta tests. Occupy's 'General Assembly' methodology, for example, is a highly flexible approach to group discussion and consensus building borrowed from the Ancient Greeks. Unlike parliamentary rules that promote debate, difference and decision, the General Assembly forges consensus by 'stacking' ideas and objections as they arise, and then making sure they are all eventually heard. The whole thing is orchestrated through simple hand gestures. Elements in the stack are prioritized, and everyone gets a chance to speak. Even after votes, exceptions and objections are incorporated as amendments.

Strangers to the process are justifiably alienated by the General Assembly, and a certain facility with its processes is required. Those who do not know the hand signals cannot readily participate. But from what I observed, newcomers quickly came to understand the General Assembly's rules, either through observation and osmosis, or the ready instruction by peers. In fact, the last place I had seen 'newbies' so quickly and deliberately oriented by more experienced participants was on the early internet.

And like many online processes, such as the 'collaborative filtering' done to bring popular results to the top of a web page, the General Assembly seems like an evolutionary leap forward in consensus-building. Dispensing with preconceived narratives about generating policy demands or settling the score between Right vs. Left, this process eschews debate (or what Enlightenment philosophers called 'dialectic') for consensus. It is a blatant rejection of the binary, winner-takes-all, political operating system of the thirteenth century.

The approach of the Occupiers is more like a university than a political movement. Both online and offline spaces consist largely of 'teach ins' about the issues they are concerned about. Young people teach one another or invite guests to lecture them about subjects such as how the economy works, the disconnection of investment banking from the economy of goods and services, possible responses to mass foreclosure, the history of centralized interest-bearing currency, and even best practices for civil disobedience. 
It is unwieldy and unpredictable, but oddly consistent with the values of a post-narrative landscape. The Occupy ethos replaces the zero-sum, closedended game of financial competition with a more sustainable, open-ended game of abundance and mutual aid. In the traditional political narrative, this sounds like communism-but to the Occupiers, it is a realization of the peer-to-peer sensibility of the social net. It is not a game that someone wins, but rather a form of play that-like a massive multiplayer online game-is successful the more people get to play, and the longer the game is kept going.

Finally, the Occupiers embody the player or hacker's approach to the political process. Each member of the movement is as capable and likely as any other to write or edit the operating system through which all of this activity takes place. Whether joining a general assembly, leading a working group, taking a role in developing or sustaining the infrastructure, or organizing an entirely new encampment, each member is free to author his or her own contribution to the total effort.

\section{Conclusion}

In the internet age, occupation could become less a form of conditional, temporary, discrete political activism than a new normative behavior. The culture of the net dissolves the boundaries between consumer and producer, programmer and user and instead promotes more of a peer-to-peer relationship between all members of the network. In a similar fashion, Occupy eschews hierarchies and defined roles in favor of modeling a new normative behavior for its participants. The occupation of Zuccotti or any other encampment is just the most pronounced version of the occupation of reality itself.

As Occupiers become conscious of the consonance of their approach with the greater emerging digital landscape, the loss of Zuccotti and other encampments becomes less significant. As McLuhan might argue, the protest encampment is merely the 'figure'- the particular content at one moment in time. The occupation concerns the 'ground' - the greater environment in which this activity is taking place. The individual players and their temporary roles mean less than the changes to the playing field itself, our understanding of the extra-political means through which the socio-economic landscape can be revised, and the trivial value of recognition from either the political parties or the mainstream corporate media. 
The Occupy movement is indeed revolutionary, but not in the sense of victory, overthrow, and replacement of authority. That cycle seeks simply to entrench a new regime (figure) within the same environment (ground). The Occupiers appear to be groping instead for something more sustainably iterative than the steady state of a single solution. The only sort of permanence in the occupation is the ongoing process of revolution, itself.

This is a politics consonant with the values and insights of twenty-firstcentury science and technology. Unlike the innovations of the industrial age, which fostered production, accumulation, central authority, and empire, those of the digital era are biased toward replication and self-modification. Robotics, genomics, nano-machines and digital programming do not render completed technologies but self-replicating, iterative systems. We program them now, but they continue themselves, learning from experience, iterating new versions, and carrying on the intentions of their original creators in novel ways.

So while the majority of public encampments and protests appear to have died down, new forms and mutations of the Occupiers' presence emerge every day. It is as if the movement is on an entirely different calendar, operating in a parallel dimension. Given the tremendous differences between the digital media environment and what went before it, this may not be an inaccurate perception. The original occupation may be 'over' as far as it is officially recognized by extant media and political authority. But as an emergent narrative, digital prototype, cultural norm, and style of play, it has only just been born.

\section{References}

Burnett, E. 2011. Out front. CNN Out Front, 3 October (E. Burnett, interviewer). Carse, J. 1997. Finite and infinite games. New York: RandomHouse.

Christopher, T. 2011. Van Susteren explains why anti-Fox clip with Occupy Wall St. protester got cut. Mediaite. http://www.mediaite.com/tv/vansusteren-explains-why-anti-fox-interview-with-occupy-wall-st-protestergot-cut.

Goodman, B. (dir. and writer), D. Rushkoff, and R. Dretzin (writers) 2003. The Persuaders. PBS Frontline. Film.

Horowitz, D. 2006. The professors: The 101 most dangerous academics in America. New York: Regenery Publishing.

Ito, J. 2011. In an open source society, innovating by the seat of our pants. The New York Times, 5 December. 
Keane, A. 2007. Cult of the amateur: How today's Internet is killing our culture. New York: Currency.

Kücklick, J. 2004. Play and playability as key concepts in new media studies. STeM Centre, Dublin City University. http://pdfs.semanticscholar.org/ge e4/25c4od353f61f 7 aobc8832dbc696d26497d5.pdf.

Logan, R. K. 1987. The alphabet effect: The impact of the phonetic alphabet on the development of Western civilization. New York: St. Martins Press.

Martinson, J. 2000. Online politics proves a turn-off. The Guardian, 27 August.

McLuhan, M. 1992. Laws of media: The new science. Toronto: University of Toronto.

-. 1962. The Gutenberg galaxy: The making of typographic man. Toronto: University of Toronto Press.

Miller, J. H., and S. E. Page. 2007. Complex adaptive systems: An introduction to computationalmodels of social life. Princeton, NJ: Princeton University Press.

Ong, W. 2002. Orality and literacy. New York: Routledge.

Pariser, E. 2011. The filter bubble: What the internet is hiding from you. New York: Penguin.

Rushkoff, D. 1995. Playing the future: How kids' culture can teach us to thrive in an age of chaos. New York: HarperEdge.

- 1998. Open source democracy: How online communication is changing offline politics. London: Demos.

- 2009. Life inc: How corporatism conquered the world and how we can take it back. New York: RandomHouse.

- 2010. There's more to being a journalist than hitting the "publish" button. Nieman Reports 64 (2): 39-40.

- 2012. Monopoly moneys: The media environment of corporatism and the player's way out. Utrecht: Utrecht University Dissertation. http://dspace. library.uu.nl/handle/1874/250622.

Simon, R. 1992. A Perot presidency and a La-Z-Boy lawmaking. Baltimore Sun, 13 May.

Sullivan, A. 2008. We are the ones we've been waiting for. The Atlantic, 28 February.

Trippi, J. 2004. The revolution will not be televised. New York: William Morrow. Weiner, N. 1965. Cybernetics, second edition, or the control and communication in the animal and the machine. Cambridge, MA: The MIT Press. 


\section{About the author}

Douglas Rushkoff is a writer, documentarian, and lecturer whose work focuses on human autonomy in a digital age. He is the author of fifteen bestselling books on media, technology, and society, including Program or be programmed (OR Books 2012), Present shock (Current 2013), and Throwing rocks at the Google bus (Portfolio 2016). Rushkoff is the recipient of the Marshall McLuhan Award for his book Coercion, The Jacques Ellul Award for his documentary The Merchants of Cool, and the Neil Postman Award for Career Achievement in Public Intellectual Activity. Named one of the world's ten most influential intellectuals by MIT, he is responsible for originating such concepts as 'viral media,' 'social currency,' and 'digital natives.' Today, Dr. Rushkoff serves as Full Professor of Media Theory and Digital Economics at CUNY/Queens, where he recently founded the Laboratory for Digital Humanism and hosts its TeamHuman podcast. He is also a research fellow at the Institute for the Future, and an advisor to Meetup, Shareable, and Codecademy. 